\title{
Burden of Unplanned Antenatal Visits in a Tertiary Hospital in Nigeria: Making a Case for an Improved Referral System
} \author{
Olofinbiyi Rebecca Oluwafunke ${ }^{3}$ \\ ${ }^{1}$ Department of Obstetrics and Gynaecology, Ekiti State University, Ado-Ekiti, Nigeria \\ ${ }^{2}$ Ekiti State University Teaching Hospital School of Nursing, Ado-Ekiti, Nigeria \\ ${ }^{3}$ Department of Nursing Science, Babcock University, Ilishan-Remo, Nigeria
}

Awoleke Jacob Olumuyiwa ${ }^{1,}$, , Olofinbiyi Babatunde Ajayi ${ }^{1}$, Awoleke Adeola Olabisi ${ }^{2}$,

Email address:

bisijacob@yahoo.co.uk (A. J. Olumuyiwa)

${ }^{*}$ Corresponding author

\section{To cite this article:}

Awoleke Jacob Olumuyiwa, Olofinbiyi Babatunde Ajayi, Awoleke Adeola Olabisi, Olofinbiyi Rebecca Oluwafunke. Burden of Unplanned Antenatal Visits in a Tertiary Hospital in Nigeria: Making a Case for an Improved Referral System. American Journal of Biomedical and Life Sciences. Vol. 7, No. 3, 2019, pp. 68-72. doi: 10.11648/j.ajbls.20190703.15

Received: June 4, 2019; Accepted: July 3, 2019; Published: July 13, 2019

\begin{abstract}
Non-urgent unplanned visits are frequently observed in pregnancy. However, there are no studies from Nigeria exploring its burden. A cross-sectional cohort survey of 1,182 women at the only state-owned teaching hospital in Ado - Ekiti was conducted to address this need. One-quarter of the population studied had unplanned antenatal visits during the period of care. Only about one in four of the reasons for the unplanned visits were 'direct' pregnancy-related complaints, while the largest proportion of the women, $227(73.5 \%)$, visited on account of infectious morbidities, followed by gastrointestinal disorders, $63(20.4 \%)$. Mothers who were skilled workers were significantly more likely to have unplanned antenatal visits compared with their unemployed counterparts $(45.3 \%$ versus $20.7 \%, \mathrm{p}=0.013)$. Unplanned visits were significantly more in women who had reduced fetal movements $(9.4 \%$ versus $0.9 \%, \mathrm{p}<0.0001)$; significantly more women who had out-ofschedule prenatal visits were admitted for care $(37.9 \%$ versus $0.2 \%, \mathrm{p}<0.0001)$, and had induction of labour $(20.1 \%$ versus $10.3 \%, \mathrm{p}<0.0001$ ) when compared with those who had no unplanned visits. Reduced maternal perception of fetal movements (odds ratio: 7.57; 95\% C. I. 3.07 - 18.70, $\mathrm{p}<0.0001$ ), prenatal admission (odds ratio: 241.81; 95\% C. I. $59.02-990.75, \mathrm{p}<$ 0.0001 ), and induction of labour (odds ratio: $1.90 ; 95 \%$ C. I. $1.24-2.93, p=0.003$ ) were found to be independently associated with unplanned antenatal visits.
\end{abstract}

Keywords: Unplanned Visits, Non-urgent, Emergency Department, Prenatal Care, Referral System, Nigeria

\section{Introduction}

Urgent or emergent medical conditions usually necessitate visits to the emergency units of various health facilities. However, studies are showing a consistent increase in the use of the emergency department for non-urgent conditions, especially in countries where health care is publicly funded [1-8]. Non-urgent use of the emergency department could be for conditions in which a delay of several hours would not lead to an increased likelihood of an adverse outcome [9]. Patients with such conditions, who could have been managed at primary or secondary levels of care, are seen in the emergency rooms of tertiary facilities, most of them by- passing the referral system [10-11]. This scenario has been associated with bogus healthcare spending, unnecessary diagnostic tests and therapies, and poorer patronage of lower tiers of the health care system. Also, the over-burdened staff within the tertiary facilities are prone to fatigue, increased personnel turn-over, and medical errors [12-14].

In most developing countries, health care is accessed via a fee-for-service because such nations do not have a national health insurance package that trickles down to the grassroots [15]. Although their tertiary facilities are usually established to cater for a broad segment of the populace, they end up providing primary and first-port-of-call care, skewed largely towards urban clientele [16]. The factors that drive this 
inappropriate use of tertiary facilities and their emergency departments in developing countries have not been adequately explored in the literature.

Unplanned visits to the emergency departments or labour rooms are common among pregnant women [17-18]. Despite the fact that they have a programmed scheme of care, half of the pregnant women in a cohort studied visited the emergency room for care during the prenatal period [19], with a proportion of these pregnant mothers using the emergency department for non-urgent reasons. This has been partly linked to the poor performance of the referral system in many developing countries, including Nigeria [20]. Thus, highly skilled manpower and facilities are expended on health conditions requiring lesser resources to deal with [21]. Is the misuse of the emergency department by obstetric patients in developing countries driven by different factors from those that obtain in the more advanced nations? Identifying factors that promote the use of the emergency department for non-urgent, unplanned antenatal visits will aid in stemming its tide, and also improve the efficiency of the health system. Being an emerging subject on the Nigerian health landscape, data that will provide information on the predictors of unplanned, non-urgent visit to tertiary facilities by pregnant women, and their influence on pregnancy management are urgently needed. These are the objectives of this study.

\section{Method}

\subsection{Study Setting}

Data for this study was extracted from an existing comprehensive database of 3477 births managed in the Department of Obstetrics and Gynaecology of the Ekiti State University Teaching Hospital, situated in Ado - Ekiti, the urban capital city of Ekiti State in southwest Nigeria, between April, 2012 and March, 2015. Ekiti State University Teaching Hospital, Ado - Ekiti is a tertiary health facility which serves as the Teaching Hospital for the College of Medicine, Ekiti State University, Ado - Ekiti, and is also an obstetric referral centre serving the private, primary and secondary health institutions within Ekiti State and its neighbouring states. Its clientele is made up of a mixture of self-presenting, health-personnel-referred, and healthfacility-transferred patients. It runs weekly antenatal clinics supervised by obstetricians. For obstetric referrals or in cases of unplanned prenatal visits, the first point of care within the hospital is the obstetric emergency room, and all care is undertaken by consultant obstetrician-led teams.

\subsection{Study Design}

Maternal socio-demographic and clinical characteristics were extracted into the database using a comprehensive proforma with ninety items covering over 180 variables, including previous gynaecological and obstetric details, index pregnancy and its progress, parturition, puerperium, observed complications, and perinatal outcomes. The data was obtained from antenatal progress records, registers in the materno-fetal medicine/antenatal ward, labour ward, maternity theatre, postnatal ward, and complemented by entries from Nurses' sheets to ensure completeness. The information was obtained in real time by a trained research assistant employed full time for that purpose. The study was approved by the Ethics and Research Committee of Ekiti State University Teaching Hospital.

Women who were not registered for antenatal care in the hospital, had severe medical illness, and multiple gestation were excluded from this study.

Case definition: Unplanned visits refer to utilization of prenatal care services outside the obstetric clinics. Nonurgent conditions in pregnancy are those in which a delay of several hours would not lead to an increased likelihood of an adverse outcome.

\subsection{Data Analysis}

The retrieved data was coded into, and analysed using the Statistical Software for the Social Sciences (SPSS) package version 20. Results were presented as percentages. Chisquare and students' t-tests were used for categorical and continuous variables respectively; variables with $p$ value < 0.05 were included in multivariate logistic regression analyses to identify the independent risk factors for unplanned antenatal visits. The results were expressed as odds ratio at $95 \%$ confidence interval (C. I.), with level of significance set at $\mathrm{p}<0.05$.

\section{Results}

Of the population studied, 309 (26.1\%) had unplanned antenatal visits during the period of care. More than onequarter, $82(26.5 \%)$, had at least two unplanned visits to the tertiary facility, with at least four-fifths, $257(83.2 \%)$, of those visits occurring in the third trimester of pregnancy. Only about one in four of the reasons for the unplanned visits were 'direct' pregnancy-related complaints, while the largest proportion of the women, 227 (73.5\%), visited on account of infectious morbidities, followed by gastrointestinal disorders, $63(20.4 \%)$ (Table 1$)$.

The relationship between the demographic and obstetric characteristics of the women and pattern of antenatal visits are as shown in Table 2. The mean age of the women was $30.67 \pm 4.50$ years, with a range of $15-47$ years. Mothers who were skilled workers were significantly more likely to have unplanned antenatal visits compared with their unemployed counterparts $(45.3 \%$ versus $20.7 \%, p=0.013)$. Unplanned visits were significantly more in women who had a live birth during the last delivery $(98.4 \%$ versus $94.4 \%, \mathrm{p}=$ 0.002 ), and who had reduced fetal movements in the index pregnancy $(9.4 \%$ versus $0.9 \%, p<0.0001)$. Also, significantly more women who had out-of-schedule prenatal visits were admitted for care $(37.9 \%$ versus $0.2 \%, \mathrm{p}<$ $0.0001)$, and had induction of labour $(20.1 \%$ versus $10.3 \%$, p $<0.0001$ ) when compared with those who had no unplanned visits. There was no significant association between 
unplanned visits and age, level of education, parity, marital status, health insurance coverage, alcohol use during pregnancy, previous history of infertility, and mode of delivery.

Results of the multivariate logistic regression analysis of the variables significantly associated with unplanned visits are shown in Table 3. Reduced maternal perception of fetal movements (odds ratio: 7.57; 95\% C. I. 3.07 - 18.70, p < 0.0001 ), prenatal admission (odds ratio: $241.81 ; 95 \%$ C. I. $59.02-990.75, \mathrm{p}<0.0001$ ), and induction of labour (odds ratio: $1.90 ; 95 \%$ C. I. $1.24-2.93, \mathrm{p}=0.003$ ) were found to be independently associated with unplanned antenatal visits.

Table 1. Overview of the unplanned antenatal visits, $n=309$.

\begin{tabular}{|c|c|}
\hline & n (\%) \\
\hline \multicolumn{2}{|l|}{ Unplanned antenatal visits } \\
\hline No & $873(73.9)$ \\
\hline Yes & $309(26.1)$ \\
\hline \multicolumn{2}{|l|}{ Number of antenatal unplanned visits } \\
\hline 1 & $227(73.5)$ \\
\hline 2 & $65(21)$ \\
\hline 3 & $17(5.5)$ \\
\hline \multicolumn{2}{|l|}{ Gestational age at the unplanned visits* } \\
\hline First trimester (Months $1-3$ ) & $21(6.8)$ \\
\hline Second trimester (Months 4 - 6) & $128(41.4)$ \\
\hline Third trimester (Months 7 - 9) & $257(83.2)$ \\
\hline \multicolumn{2}{|l|}{ Reasons for unplanned visits* } \\
\hline \multicolumn{2}{|l|}{ 1. Pregnancy-related complaints } \\
\hline Reduced fetal movements & $24(7.8)$ \\
\hline Antepartum haemorrhage & $12(3.9)$ \\
\hline Spurious labour & $10(3.2)$ \\
\hline Threatened miscarriage & $9(2.9)$ \\
\hline Preterm rupture of membranes & $8(2.6)$ \\
\hline Preterm labour & $6(1.9)$ \\
\hline Gestational Diabetes Mellitus & $4(1.3)$ \\
\hline Hyperemesis gravidarum & $4(1.3)$ \\
\hline Pregnancy-induced hypertension & $3(1.0)$ \\
\hline Degenerating fibroids in pregnancy & $1(0.3)$ \\
\hline Intrauterine growth restriction & $1(0.3)$ \\
\hline \multicolumn{2}{|l|}{ 2. Infectious morbidity } \\
\hline Malaria infestation & $149(48.2)$ \\
\hline Respiratory tract infection & $35(11.3)$ \\
\hline Skin sepsis & $25(8.1)$ \\
\hline Gastroenteritis & $18(5.8)$ \\
\hline \multicolumn{2}{|l|}{ 3. Gastrointestinal disorders } \\
\hline Abdominal pain & $52(16.8)$ \\
\hline Gastro-oesophageal reflux disorder & $8(2.6)$ \\
\hline Haemorrhoids & $2(0.6)$ \\
\hline Constipation & $1(0.3)$ \\
\hline 4. Urinary conditions & $19(6.1)$ \\
\hline \multicolumn{2}{|l|}{ 5. Respiratory conditions } \\
\hline Asthma & $2(0.6)$ \\
\hline \multicolumn{2}{|l|}{ 6. Musculoskeletal conditions } \\
\hline Back ache & $10(3.2)$ \\
\hline$*$ Total $>100 \%$ because of multiple $r$ & \\
\hline
\end{tabular}

Table 2. Relationship between the demographic and obstetric characteristics of the women and pattern of antenatal visits.

\begin{tabular}{|c|c|c|c|c|}
\hline Variables & Categories & $\begin{array}{l}\text { Unplanned } \\
\text { visits }\end{array}$ & $\begin{array}{l}\text { No unplanned } \\
\text { visits }\end{array}$ & $p$ value \\
\hline & & n (\%) & n (\%) & \\
\hline Age (years) & Mean \pm SD & $30.48 \pm 4.36$ & $30.73 \pm 4.55$ & 0.404 \\
\hline \multirow[t]{2}{*}{$\begin{array}{l}\text { Age group } \\
\text { (years) }\end{array}$} & $<30$ & $124(40.1)$ & $361(41.4)$ & 0.707 \\
\hline & $\geq 30$ & 185 (59.9) & $512(58.6)$ & \\
\hline \multirow[t]{2}{*}{ Marital status } & Single & $1(0.3)$ & $3(0.3)$ & 0.958 \\
\hline & Married & 308 (99.7) & 870 (99.7) & \\
\hline \multirow[t]{4}{*}{$\begin{array}{l}\text { Level of } \\
\text { education }\end{array}$} & No formal & $0(0)$ & $1(0.1)$ & 0.369 \\
\hline & Primary & $1(0.3)$ & $13(1.5)$ & \\
\hline & Secondary & $39(12.6)$ & $116(13.3)$ & \\
\hline & Tertiary & $269(87.1)$ & $743(85.1)$ & \\
\hline \multirow[t]{4}{*}{ Occupation } & Unemployed & $64(20.7)$ & $156(17.9)$ & $0.013 *$ \\
\hline & Unskilled & $68(22)$ & $208(23.8)$ & \\
\hline & Semi-skilled & 37 (12) & $59(6.8)$ & \\
\hline & Skilled & $140(45.3)$ & $450(51.5)$ & \\
\hline \multirow[t]{3}{*}{ Parity } & 0 & $127(41.1)$ & 309 (35.4) & 0.181 \\
\hline & $1-4$ & $180(58.3)$ & $555(63.6)$ & \\
\hline & $\geq 5$ & $2(0.6)$ & $9(1)$ & \\
\hline \multirow[t]{2}{*}{$\begin{array}{l}\text { Health } \\
\text { insurance }\end{array}$} & No & $299(96.8)$ & 855 (97.9) & 0.243 \\
\hline & Yes & $10(3.2)$ & $18(2.1)$ & \\
\hline \multirow[t]{2}{*}{ Alcohol } & No & 306 (99) & 869 (99.5) & 0.313 \\
\hline & Yes & $3(1)$ & $4(0.5)$ & \\
\hline \multirow[t]{2}{*}{$\begin{array}{l}\text { Previous } \\
\text { infertility }\end{array}$} & No & $297(96.1)$ & 854 (97.8) & 0.107 \\
\hline & Yes & $12(3.9)$ & $19(2.2)$ & \\
\hline \multirow[t]{2}{*}{$\begin{array}{l}\text { Assisted } \\
\text { conception }\end{array}$} & No & $306(99)$ & $871(99.8)$ & 0.084 \\
\hline & Yes & $3(1)$ & $2(0.2)$ & \\
\hline \multirow[t]{2}{*}{$\begin{array}{l}\text { Gestational } \\
\text { DM }\end{array}$} & No & 295 (95.5) & $836(95.8)$ & 0.828 \\
\hline & Yes & $14(4.5)$ & $37(4.2)$ & \\
\hline \multirow[t]{2}{*}{ Pre-eclampsia } & No & 295 (95.5) & 852 (97.6) & 0.058 \\
\hline & Yes & $14(4.5)$ & $21(2.4)$ & \\
\hline \multirow[t]{2}{*}{$\begin{array}{l}\text { Last } \\
\text { pregnancy }\end{array}$} & Stillbirth & $4(1.3)$ & $49(5.6)$ & $0.002 *$ \\
\hline & Live birth & 305 (98.7) & $824(94.4)$ & \\
\hline \multirow[t]{2}{*}{$\begin{array}{l}\text { Reduced } \\
\text { kicks }\end{array}$} & No & $280(90.6)$ & $865(99.1)$ & $<0.0001^{*}$ \\
\hline & Yes & $29(9.4)$ & $8(0.9)$ & \\
\hline \multirow[t]{2}{*}{$\begin{array}{l}\text { Labour } \\
\text { induction }\end{array}$} & No & 247 (79.9) & 783 (89.7) & $<0.0001^{*}$ \\
\hline & Yes & $62(20.1)$ & $90(10.3)$ & \\
\hline \multirow[t]{2}{*}{$\begin{array}{l}\text { Route of } \\
\text { delivery }\end{array}$} & Vaginal & 207 (67) & $588(67.4)$ & 0.907 \\
\hline & Abdominal & $102(33)$ & $285(32.6)$ & \\
\hline \multirow[t]{2}{*}{$\begin{array}{l}\text { Prenatal } \\
\text { admission }\end{array}$} & No & $192(62.1)$ & 871 (99.8) & $<0.0001^{*}$ \\
\hline & Yes & 117 (37.9) & $2(0.2)$ & \\
\hline \multirow[t]{2}{*}{$\begin{array}{l}\text { Pregnancy } \\
\text { outcome }\end{array}$} & Stillbirth & $5(1.6)$ & $5(0.6)$ & 0.085 \\
\hline & Live birth & $304(98.4)$ & $868(99.4)$ & \\
\hline \multirow{3}{*}{$\begin{array}{l}\text { EGA at } \\
\text { delivery } \\
\text { Delivery age } \\
\text { (weeks) }\end{array}$} & Mean \pm SD & $38.25 \pm 2.31$ & $38.43 \pm 2.29$ & 0.230 \\
\hline & $\leq 40$ & $266(86.1)$ & $732(83.8)$ & 0.352 \\
\hline & $>40$ & 43 (13.9) & $141(16.2)$ & \\
\hline
\end{tabular}

*significant at $\mathrm{p}<0.05$ 
Table 3. Logistic regression analysis of the factors associated with unplanned antenatal visits.

\begin{tabular}{lllll}
\hline Characteristics & $\begin{array}{l}\text { Odds } \\
\text { ratio }\end{array}$ & $\begin{array}{l}\text { 95\% Confidence } \\
\text { Interval }\end{array}$ & p value & Reference \\
\hline Prenatal admission & 241.81 & $59.02-990.75$ & $<0.0001 *$ & No admission \\
Live birth & 3.21 & $1.00-10.25$ & 0.050 & Stillbirth \\
Reduced kicks & 7.57 & $3.07-18.70$ & $<0.0001 *$ & Adequate kicks \\
Labour induction & 1.90 & $1.24-2.93$ & $0.003 *$ & No induction \\
Skilled workers & 0.81 & $0.53-1.25$ & 0.350 & Unemployed \\
\hline
\end{tabular}

*significant at $\mathrm{p}<0.05$

\section{Discussion}

Although there are sparse studies showing the burden of non-urgent use of the emergency department of tertiary hospitals by non-pregnant clients in Nigeria [10], we found no study strictly among the obstetric population. Thus, findings from this study are the first to document the burden of unplanned antenatal visits in a tertiary facility in a low resource setting.

Similar to findings from an American study [22], this study revealed that unplanned hospital visits are common in pregnancy, even among women with established care-givers. Interestingly, only one-quarter of these visits were for specific pregnancy-related complaints, with over threequarters of the visits secondary to other medical/surgical (and, mainly non-urgent) conditions. This is contrary to the findings from a study by Magriples et al [22], which revealed that more than half of the unscheduled prenatal visits were for obstetric complications, with only $10 \%$ being secondary to other medical/surgical issues. The observed differences could be due to the fact that their study participants were aged 25 years and below, had complete prenatal insurance coverage, and did not include visits that ended in an admission. However, the implication of our finding is that obstetric patients with milder, non-obstetric conditions skip consulting primary or secondary care facilities to access care in the emergency departments of tertiary hospitals. This could result in an increase in the burden on the emergency room staff, making it more difficult for them to care for severely ill patients [11]. Educating the populace on what constitutes urgent obstetric complications, and providing accessible and effective care for medical/surgical issues, especially infectious morbidities occurring in pregnancy, at the secondary facilities are advocated.

Skilled workers, who are potentially more financially empowered, were significantly more likely to have unplanned visits during pregnancy. Since the costs of antenatal care have been shown to be greater with unscheduled prenatal visits [22-23], they are more likely to be able to afford the higher costs. Other socio-demographic variables have not shown a consistent association in the published literature with unplanned antenatal visits [9]. This could be due to variations in the criteria used to select the study participants, their perception of their symptoms, the general health-seeking behaviour of the community etc.

Understandably, the index study found that mothers who had a reduction in their perceived fetal movements were more likely to have unplanned hospital visits. These extra visits could be needed to ascertain the complaint, identify a possible cause, and institute therapeutic interventions. Also, our study found that women with unplanned visits were more likely to be admitted for in-patient care. We hypothesize that, although the proportion of women with 'direct' obstetric complications was smaller, those complaints were important enough to warrant hospitalization, and possibly delivery, a fact corroborated by the findings that more mothers had unplanned visits in the third trimester of pregnancy, and also had significantly higher rates of labour induction. Increased staffing of the obstetric units and improved infrastructure (including electronic fetal surveillance techniques) in the secondary care facilities would better equip them to effectively manage obstetric complications, thereby reducing the burden of unplanned visits on tertiary facilities. The establishment of national management guidelines for various obstetric complications, coupled with an efficient and effective referral system would mean that the quantity of clients utilizing tertiary facilities for non-urgent conditions will diminish, while the quality of care provided by lower health facilities will improve.

This survey may be limited by the definition of non-urgent conditions, as $3 \%-5 \%$ of cases that were initially adjudged to be non-urgent at presentation required immediate hospitalization on closer evaluation in the emergency room [24]. Besides, the study is a tertiary facility-based survey of largely fee-paying clients with a scheduled prenatal care arrangement. Thus, it may make generalization of the findings to other population of obstetric patients in lower tiers of health facilities difficult. Future research on the subject would benefit from the data provided by this study to address these limitations.

\section{Conclusion}

Unplanned prenatal visits are frequently observed, even among pregnant women in a routine programme of care. Most of these visits, however, were for milder, non-obstetric conditions, especially infectious morbidities. These out-ofschedule visits were also predicted by reduced maternal perception of fetal movements, resulting in significantly more prenatal hospitalizations and labour induction. Educating the populace on what constitutes urgent obstetric complications, and scaling up care at the secondary facilities are advocated. Increased staffing of the obstetric units and improved infrastructure (including electronic fetal surveillance techniques) in the secondary care facilities would better equip them to effectively manage obstetric complications, thereby reducing the burden of unplanned visits on tertiary facilities. The establishment of national management guidelines for various obstetric complications, coupled with an efficient and effective referral system are indispensable, if we must reduce the burden of unplanned visits and the overall cost of prenatal care. 


\section{Acknowledgements}

The authors wish to acknowledge the contributions of Sunday Ibiyemi, the nursing staff, residents and Consultants of the Department of Obstetrics and Gynaecology, Ekiti State University Teaching Hospital, Ado - Ekiti.

\section{Conflict of Interest Statement}

All the authors do not have any possible conflicts of interest.

\section{References}

[1] Northington W, Brice J, Zou B. Use of an emergency department by non-urgent patients. American Journal of Emergency Medicine 2005; 23: 131-137.

[2] Guttman N, Zimmerman D, Nelson M. The Many Faces of Access: Reasons for Medically Non-urgent Emergency Department Visits. Journal of Health Politics, Policy and Law 2003; 28 (6): 1089-120.

[3] Kellerman A. Nonurgent emergency department visits. JAMA 1994; 271: 1953-1955.

[4] Redstone P, Vancura J, Barry D, Kutner J. Nonurgent Use of the Emergency Department. J Ambulatory Care Manage 2008; 31 (4): 370-376.

[5] Phelps K, Taylor C, Kimmel S, Nagel R, Klein W, Puczynski S. Factors associated with emergency department utilization for nonurgent pediatric problems. Arch Fam Med 2000; 9: 1086-1092.

[6] Carret M, Fassa A, Kawachi I. Demand for emergency health service: factors associated with inappropriate use. BMC Health Services Research 2007; 7: 131.

[7] Cunningham P, Clancy C, Cohen J, Wilets M. The use of hospital emergency departments for nonurgent health problems. Medical Case Research and Review 1995; 52 (4): 453-474.

[8] Weinick R, Burns R, Mehrotra A. Many emergency department visits could be managed at urgent care centers and retail clinics. Health Affairs 2010; 29 (9): 1630-1636.

[9] Uscher-Pines L, Pines J, Kellermann A, Gillen E, Mehrotra A. Deciding to visit the emergency department for non-urgent conditions: a systematic review of the literature. Am J Manag Care 2013; 19 (1): 47-59.

[10] Akande TM. Referral system in Nigeria: study of a tertiary health facility. Annals of African Medicine 2004; 3 (3): 130-3.

[11] Kadooka Y, Asai A, Enzo A, Okita T. Misuse of emergent healthcare in contemporary Japan. BMC Emerg Med 2017; 17: 23.

[12] Trezeciak S, Rivers EP. Emergency department overcrowding in the United States: an emerging threat of patient safety and public health. Emerg Med J 2003; 20: 402-5.

[13] Bayley MD, Schwartz JS, Shofer FS, Weiner M, Sites FD, Traber KB, Hollander JE. The financial burden of emergency department congestion and hospital crowding for chest pain patients awaiting admission. Ann Emerg Med 2005; 45: 110-7.

[14] Derlet RW, Richards JR. Overcrowding in the nation's emergency departments; complex causes and disturbing effect. Ann Emerg Med 2000; 35: 63-8.

[15] Pauly MV, Zweifel P, Scheffler RM, Preker AS, Bassett M. Private health insurance in developing countries. Health Affairs 2006; $25 \quad$ (2). https://doi.org/10.1377/hlthaff.25.2.369.

[16] Dunne MO, Martin AJ. The appropriateness of A and E attendances: a prospective study. Ireland Med J 1997; 90: 2689.

[17] Kotelchuck M. The adequacy of prenatal care utilization index. Its U.S. distribution and association with low birthweight. Am J Public Health 1994; 84: 1486-9.

[18] Kogan MD, Martin JA, Alexander GR, Kotelchuck M, Ventura SJ, Frigoletto FD. The changing pattern of prenatal care utilization in the United States, 1981-1995, using different prenatal care indices. JAMA 1998; 279: 1623-8.

[19] Kilfoyle KA, Vrees R, Raker CA, Matteson KA. Non-urgent and urgent emergency department use during pregnancy: an observational study. Am J Obstet Gynecol 2017; 26 (2): 181.e1-181.e7.

[20] Bossyns P, van Lerberghe W. The weakest link: competence and prestige as constraints to referral by isolated nurses in rural Niger. BMC Human Resources for Health 2004; 2: 1-8.

[21] Laffoy M, O'Herlihy B, Keye G. A profile of attendees to a south Dublin city accident and emergency department. Ireland J Med Sci 1997; 166: 35-7.

[22] Magriples U, Kershaw TS, Rising SS, Massey Z, Ickovics JR. Prenatal health care beyond the obstetrics service: Utilization and predictors of unscheduled care. Am J Obstet Gynecol 2008; 198 (1): 75.e1-75.e7.

[23] World Bank: Development in practice. Better health in Africa: experience and lessons learned. Word Bank Publication, 1994; 45-51.

[24] Young GP, Wagner MB, Kellermann AL, Ellis J, Bouley D. Ambulatory visits to hospital emergency departments. Patterns and reasons for use. 24 Hours in the ED Study Group. JAMA 1996; 276 (6): 460-465. 